\title{
Amplifiers Module Prototype for the Johnson Noise Thermometry System
}

\section{June 2013}

Prepared by

Charles L. Britton Jr.

Nora D. Bull

Michael Roberts

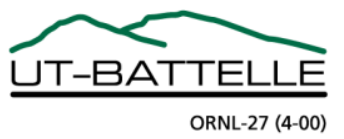




\title{
DOCUMENT AVAILABILITY
}

Reports produced after January 1, 1996, are generally available free via the U.S. Department of Energy (DOE) Information Bridge.

Web site http://www.osti.gov/bridge

Reports produced before January 1, 1996, may be purchased by members of the public from the following source.

\author{
National Technical Information Service \\ 5285 Port Royal Road \\ Springfield, VA 22161 \\ Telephone 703-605-6000 (1-800-553-6847) \\ TDD 703-487-4639 \\ Fax 703-605-6900 \\ E-mail info@ntis.gov \\ Web site http://www.ntis.gov/support/ordernowabout.htm
}

Reports are available to DOE employees, DOE contractors, Energy Technology Data Exchange (ETDE) representatives, and International Nuclear Information System (INIS) representatives from the following source.

Office of Scientific and Technical Information

P.O. Box 62

Oak Ridge, TN 37831

Telephone 865-576-8401

Fax 865-576-5728

E-mail reports@osti.gov

Web site http://www.osti.gov/contact.html

This report was prepared as an account of work sponsored by an agency of the United States Government. Neither the United States Government nor any agency thereof, nor any of their employees, makes any warranty, express or implied, or assumes any legal liability or responsibility for the accuracy, completeness, or usefulness of any information, apparatus, product, or process disclosed, or represents that its use would not infringe privately owned rights. Reference herein to any specific commercial product, process, or service by trade name, trademark, manufacturer, or otherwise, does not necessarily constitute or imply its endorsement, recommendation, or favoring by the United States Government or any agency thereof. The views and opinions of authors expressed herein do not necessarily state or reflect those of the United States Government or any agency thereof. 
ORNL/TM-2013/22

SMR/ICHMI/ORNL/TR-2013/01

\title{
AMPLIFIERS MODULE PROTOTYPE FOR THE JOHNSON NOISE THERMOMETRY SYSTEM
}

\author{
Author(s) \\ Charles L. Britton Jr \\ Nora D. Bull \\ Michael Roberts
}

Date Published: June 2013

\author{
Prepared by \\ OAK RIDGE NATIONAL LABORATORY \\ Oak Ridge, Tennessee 37831-6283 \\ managed by \\ UT-BATTELLE, LLC \\ for the \\ U.S. DEPARTMENT OF ENERGY \\ under contract DE-AC05-00OR22725
}




\section{CONTENTS}

\section{Page}

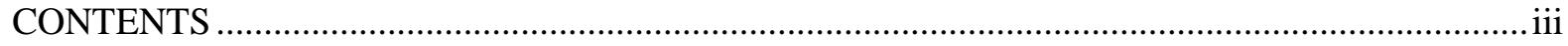

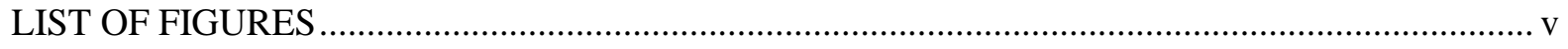

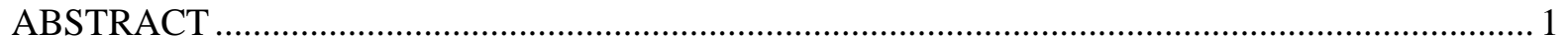

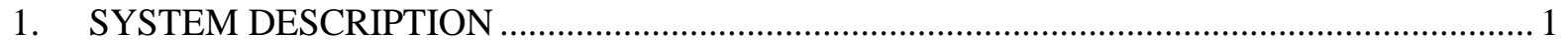

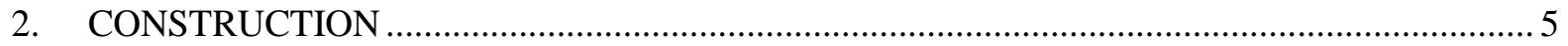

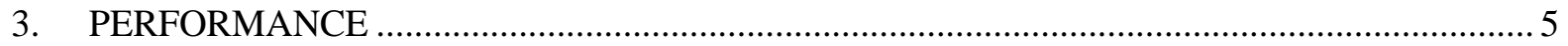

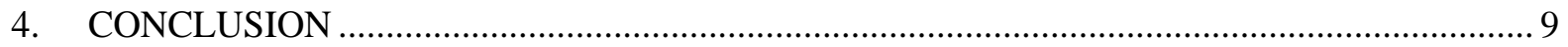

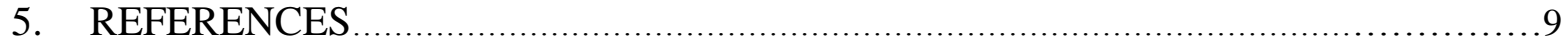




\section{LIST OF FIGURES}

Figure

Page

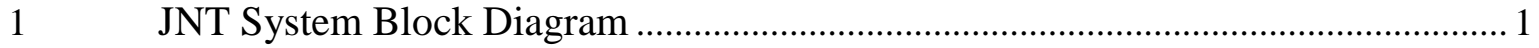

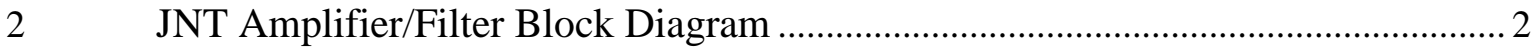

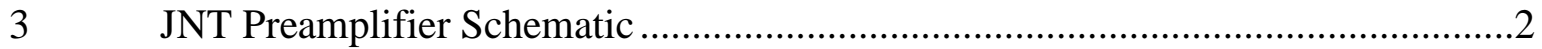

4 Bandpass Filter/Gain Schematic .........................................................................

$5 \quad$ Lowpass filter with unity-gain amplifier configuration $(\mathrm{K}=1)$.......................... 4

$6 \quad$ Highpass filter with unity-gain amplifier configuration $(\mathrm{K}=1)$..........................4

$7 \quad$ Lowpass filter with switched resistors added ..............................................

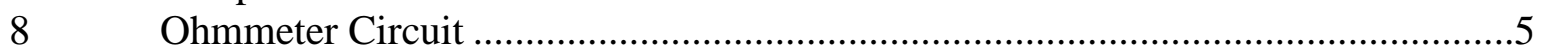

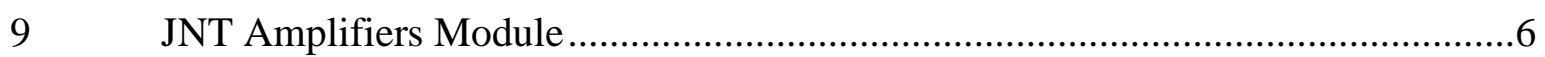

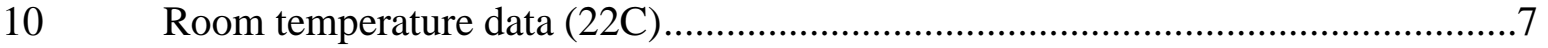

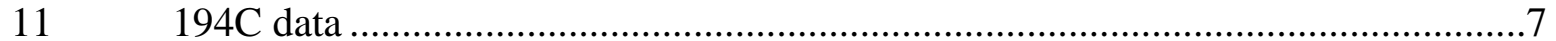

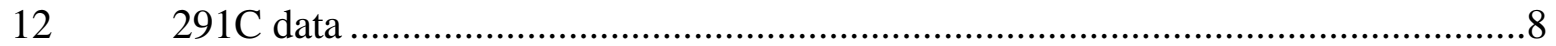

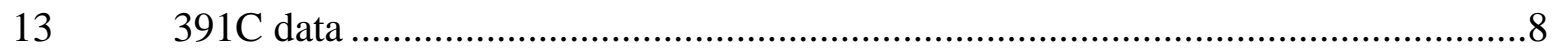




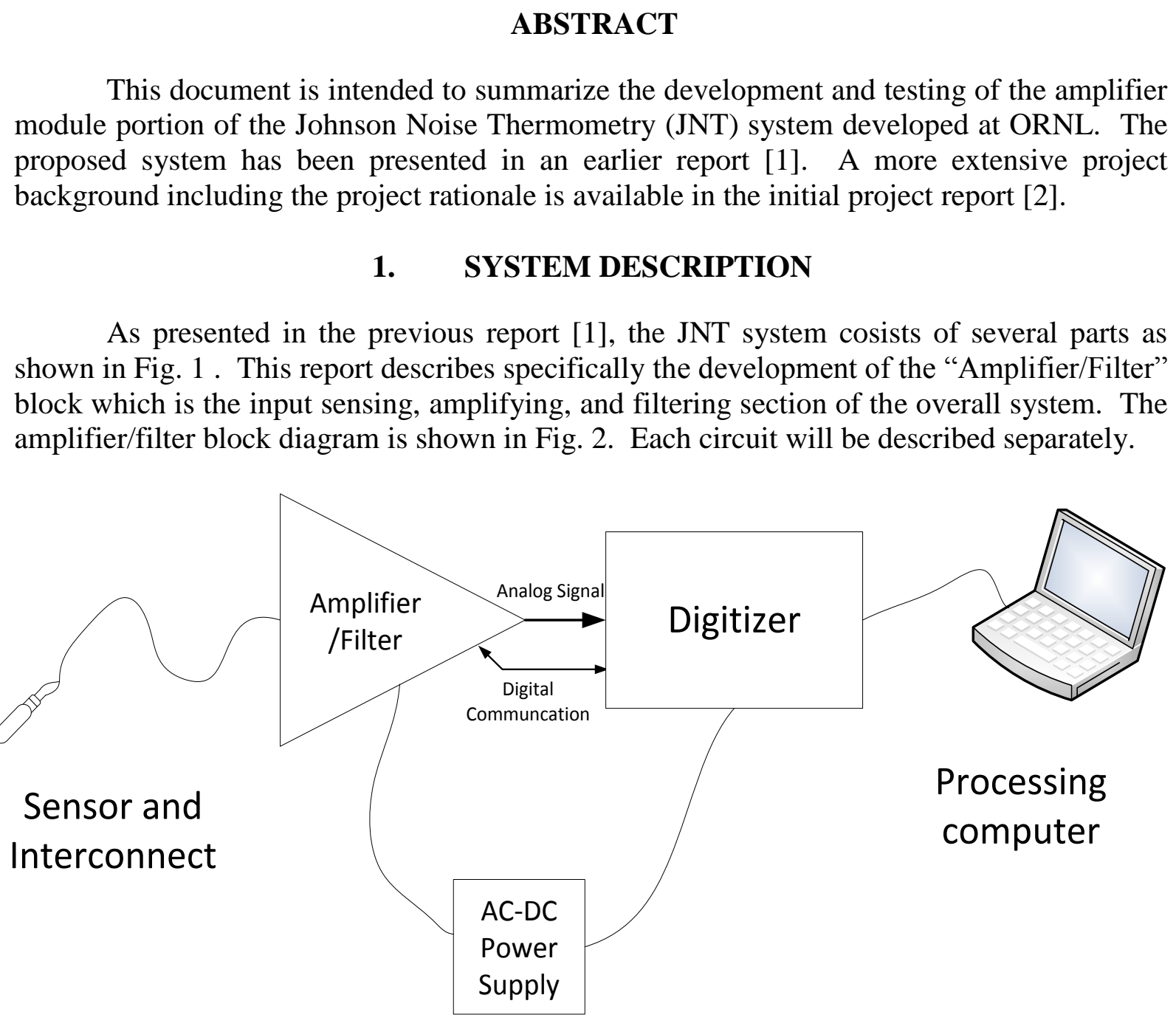

Fig. 1. JNT System Block Diagram.

1. Preamplifier. The noise signal from the RTD sensor is extremely small and needs to be sensed with an appropriate preamplifier. This means a preamplifier with very low inherent noise and relatively high gain. The low noise is required so that the preamplifier injects the least possible amount of its own noise into the signal which would result in an incorrect reading. The gain is required so that the very small noise signal amplitude can be increased to a point where the electronic noise of successive stages will not also become a significant source of error.

The RTD noise is sensed differentially by two independent channels which are treated as separate but equal amplifier chains. The signal at each of the two channel outputs contains primarily the sensor noise plus a small amount of noise from the filters and the other amplifiers. The final software processing of the signals includes routines to autocorrelate the noise between the two channels. The only signal of interest that is in both channels is the desired sensor noise so that the autocorrelation removes other electronic noise from the amplifiers and filters. 


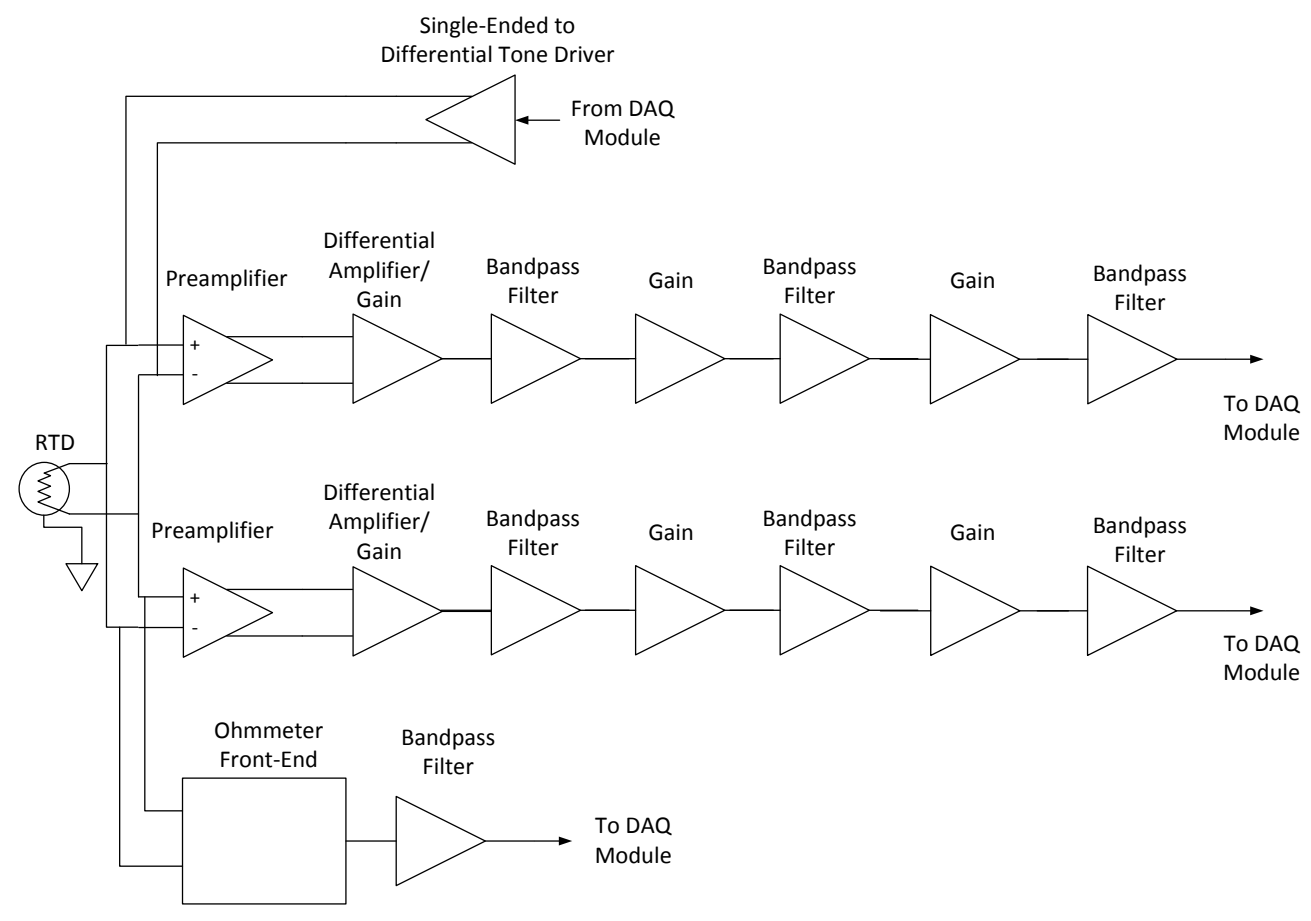

Fig. 2. JNT Amplifier/Filter Block Diagram.

The preamplifer designed for this is shown in Fig. 3. The topology is that of a fullydifferential amplifier utilizing junction field-effect transistors (JFETs) for the input devices. The output drains of the JFETs feed high-gain folded-cascode amplifier chains which

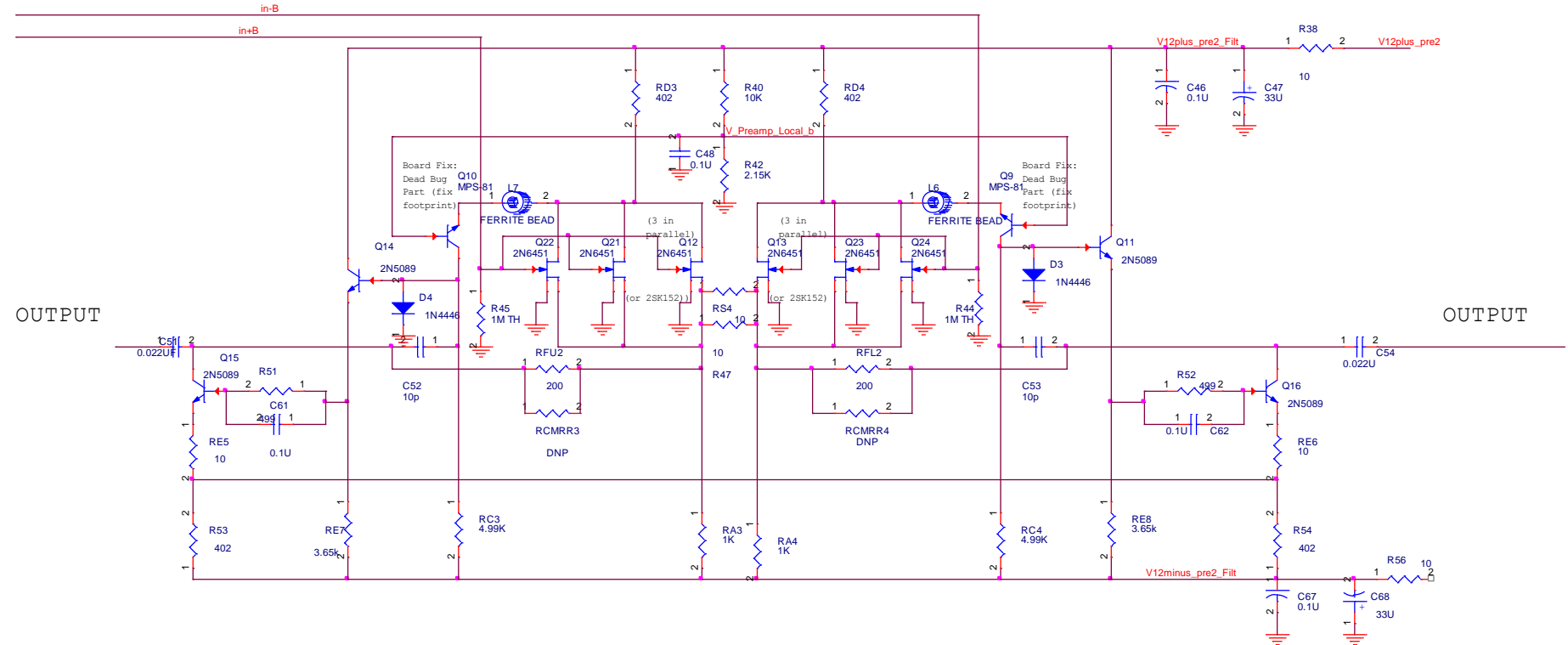

Fig. 3. JNT Preamplifier Schematic.

implement a symmetrical set of differential output paths while also providing common-mode feedback (CMFB) to the input stages. This enables the fully-differential structure to provide 
the desired differential-in/differential-out topology while ensuring appropriate dc circuit stability for the entire preamplifier circuit. Each channel contains one of these preamplifiers. The differential gain of this preamplifier is approximately $80 \mathrm{~V} / \mathrm{V}$.

2. Differential Amplifier/Gain. The output of the differential preamplifier contains the desired noise of the resistor but also contains the common-mode noise of extraneous pickup in the sensor lines. In order to remove the undesired pickup noise we process the differential preamplifier output with a differential amplifier which passes the resistor signal and cancels the pickup.

3. Bandpass Filter/Gain. The bandpass filter design, shown in Fig. 4, utilizes the Sallen-key filter topology to implement the high-pass and low-pass functions. The SallenKey (SK) filter was chosen for this application for two reasons. First, the SK filter utilizes a finite-gain operational amplifier configuration which maintains a stable transfer function over variations in operational amplifier performance thus simplifying the choice of amplifiers in the design. Second, the filter design is relatively simple since each second-order filter block is entirely independent of the others.

The desired filter is a fourth order filter with transfer function denominator polynomials of $1+2.6131 s+3.4142 \mathrm{~s}^{2}+2.6131 \mathrm{~s}^{3}+\mathrm{s}^{4}=\left(\mathrm{s}^{2}+0.7654 \mathrm{~s}+1\right)\left(\mathrm{s}^{2}+1.8478 \mathrm{~s}+1\right)$. The filter consists of multiple stages: highpass filter, lowpass filter, gain stage, highpass filter, and final lowpass filter. The highpass and lowpass filters are separated into two stages to allow for reduced component sensitivity which makes the circuit less sensitive to temperature.

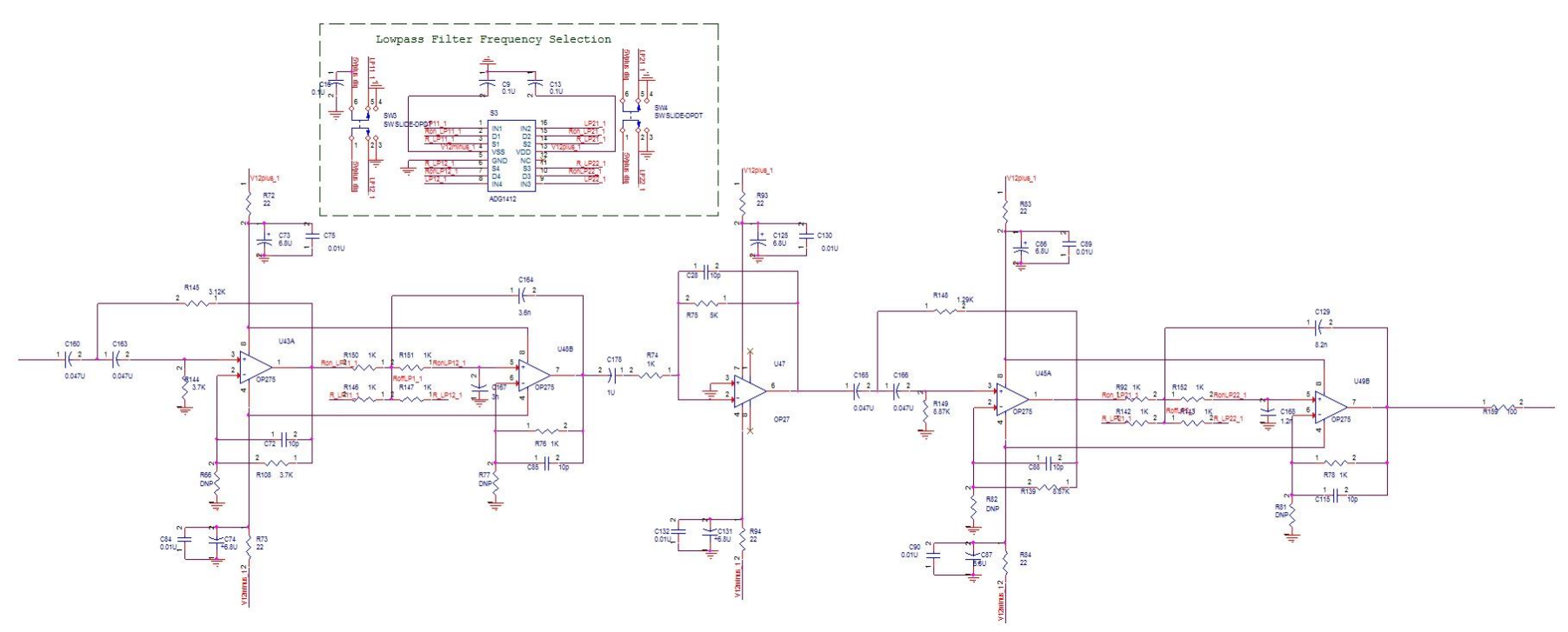

Fig. 4. Bandpass Filter/Gain Schematic.

Using the desired polynomials, choosing pole placement at $1 \mathrm{kHz}$ for the highpass filter and switchable frequencies between $50 \mathrm{kHz}$ and $100 \mathrm{kHz}$ for the lowpass filter, the following equations can be used to solve for the required resistor and capacitor values. To set the cutoff frequency (pole locations), these polynomials needed to be shifted. The following shifted polynomials were calculated: $\mathrm{HP}(1 \mathrm{kHz})=\left(2.533 \times 10^{-8} \mathrm{~s}^{2}+1.218 \times 10^{-4} \mathrm{~s}+1\right)\left(2.533 \times 10^{-8} \mathrm{~s}^{2}+\right.$ $\left.2.941 \times 10^{-4} \mathrm{~s}+1\right) ; \mathrm{LP}(100 \mathrm{kHz})=\left(2.533 \times 10^{-12} \mathrm{~s}^{2}+1.218 \times 10^{-6} \mathrm{~s}+1\right)\left(2.533 \times 10^{-12} \mathrm{~s}^{2}+2.941 \times 10^{-}\right.$ $\left.{ }^{6} \mathrm{~s}+1\right) ; \mathrm{LP}(50 \mathrm{kHz})=\left(1.013 \times 10^{-11} \mathrm{~s}^{2}+2.436 \times 10^{-6} \mathrm{~s}+1\right)\left(1.013 \times 10^{-11} \mathrm{~s}^{2}+5.882 \times 10^{-6} \mathrm{~s}+1\right)$. 


\section{Lowpass Filter design:}

Transfer Function:

$$
H(s)=\frac{K / R_{1} R_{2} C_{1} C_{2}}{s^{2}+s\left[\frac{1}{R_{1} C_{1}}+\frac{1}{R_{2} C_{1}}+\frac{1-K}{R_{2} C_{2}}\right]+\frac{1}{R_{1} R_{2} C_{1} C_{2}}}
$$

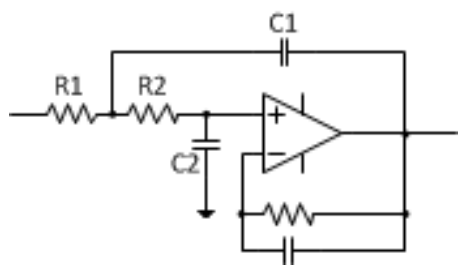

$\mathrm{K}$ = gain of amplifier

Choose $\mathrm{R} 1=\mathrm{R} 2$

$\omega_{0}=$ cutoff frequency

Fig. 5. Lowpass filter with unity-gain

amplifier configuration $(\mathrm{K}=1)$

$\mathrm{Q}=$ quality factor $=2 \pi$ (Engery Stored/Power Loss)

$\mathrm{C} 1=2 \mathrm{Q} / \mathrm{R} \omega_{0}$

$\mathrm{C} 2=1 / 2 \mathrm{QR} \omega_{0}$

The gain is configurable through a resistor deividor on the negative input of the amplifier. (see Fig. 4)

Highpass Filter design:

Transfer Function:

$H(s)=\frac{K s^{2}}{s^{2}+s\left[\frac{1}{R_{2} C_{1}}+\frac{1}{R_{2} C_{2}}+\frac{1-K}{R_{1} C_{1}}\right]+\frac{1}{R_{1} R_{2} C_{1} C_{2}}}$

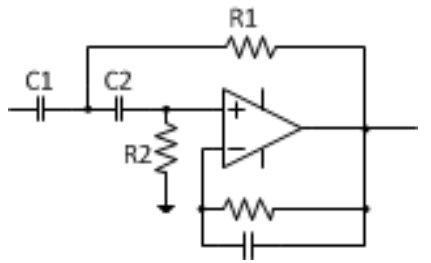

Choose $\mathrm{C} 1=\mathrm{C} 2$

$\mathrm{R} 1=1 / 2 \mathrm{QC} \omega_{0}$

$\mathrm{R} 2=2 \mathrm{Q} / \mathrm{C} \omega_{0}$

Fig. 6. Highpass filter with unity-gain amplifier configuration $(\mathrm{K}=1)$.

To allow for a flexible bandwidth of the filter, a switch was added to enable shifting of the lowpass cutoff frequency between $50 \mathrm{kHz}$ or $100 \mathrm{kHz}$. To implement the switching ability, the capacitors are kept constant and the resistance is changed. Fig. 7 displays the implementation of this. The addition of the two resistors $\mathrm{R} 11$ and $\mathrm{R} 22$ reduces the resistance of the network by a factor of two thus shifting the frequency from $50 \mathrm{kHz}$ to $100 \mathrm{kHz}$.

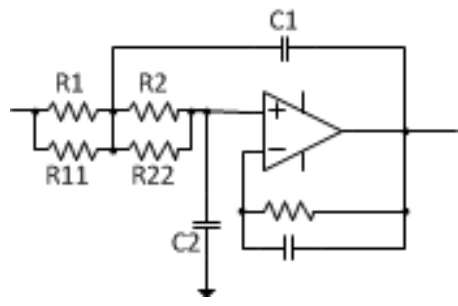

Fig. 7. Lowpass filter with switched resistors added. 


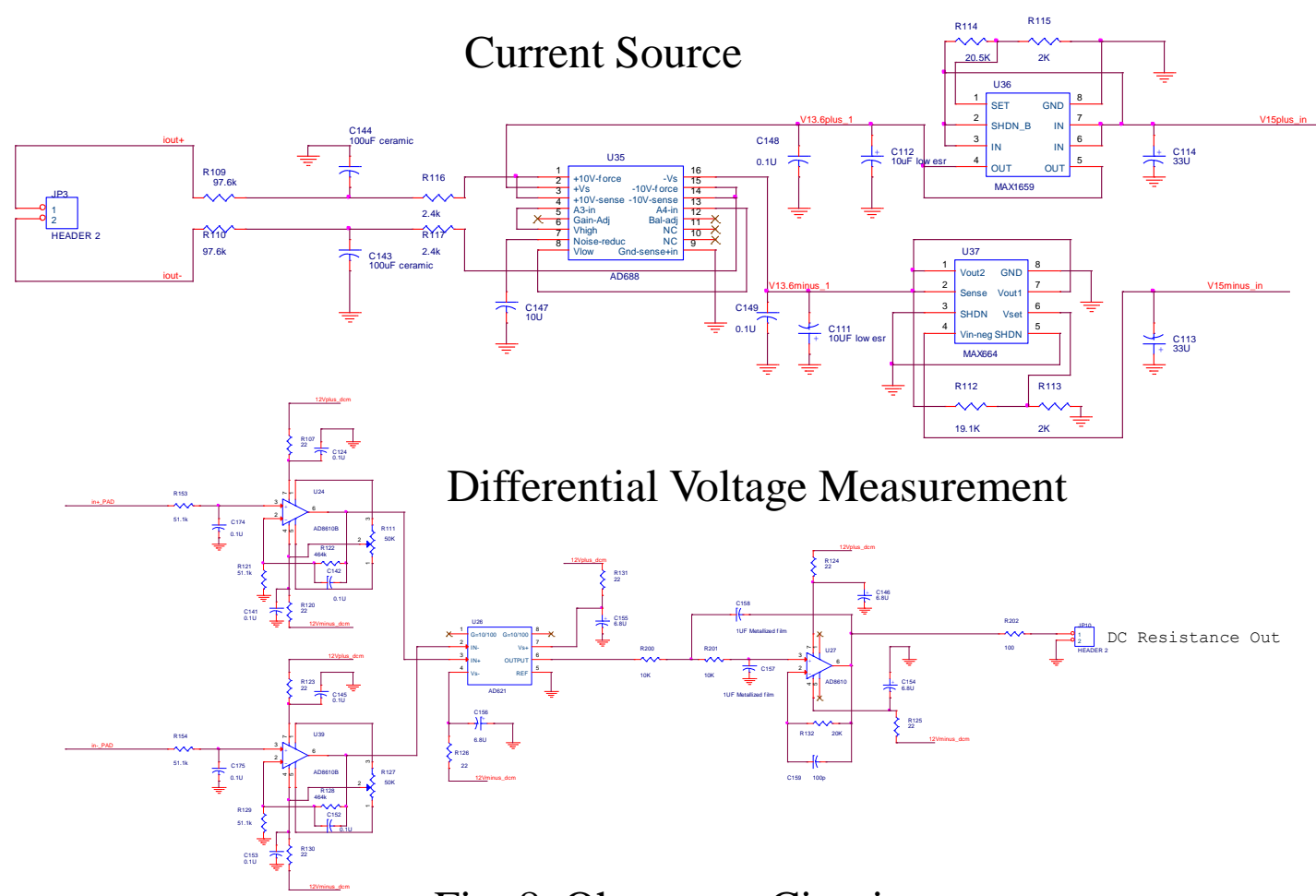

Fig. 8 Ohmmeter Circuit

3. Ohmmeter Front-End/Bandpass Filter. For the DC resistance measurement (ohmmeter), a 100- $\mu \mathrm{A}$ current is supplied to the RTD through the AD688 complementary voltage reference (U35 in Fig. 8) and the series resistors (R109, R110). The differential amplifier section shown in Fig. 8 measures the voltage drop across the RTD and outputs an amplified voltage to the two-pole Sallen-Key filter which then is fed to the data-acquisition module. Since this is a 4-wire measurement, the current is supplied through one set of wires to the RTD and the voltage is measured across the remaining set of wires.

\section{CONSTRUCTION}

The module was designed and fabricated with all components on a single printedcircuit board. It was placed inside a zinc box with connectors on the outside. Power is supplied from a dual $+/-15-\mathrm{V}$ linear supply. The noise outputs are fed into a circuit board that performs additional gain and filtering but will be replaced with a new, smaller board in the next phase of the project. The analog-digital converters and the pilot tone are supplied by the Agilent 2531A data-acquistion module which will likely be the device used for the next phase of the project. A picture of the board is shown in Fig. 9 with the copper shields on the left covering the preamplifiers. The two noise channels are at the top and bottom of the picture and the ohmmeter circuit is in the middle. Signal flow is right to left.

\section{PERFORMANCE}

To date the module has been tested extensively with the existing system and has performed exceptionally well. By itself the module has performed exactly as expected and 
has proven to be exceptionally stable. A great number of data runs have been perfomed during which some software issues have been discovered and are in the process of being addressed. The only issue we have seen with the module was in the beginning, one of the voltage regulators which supply the precision current source for the ohmmeter did not

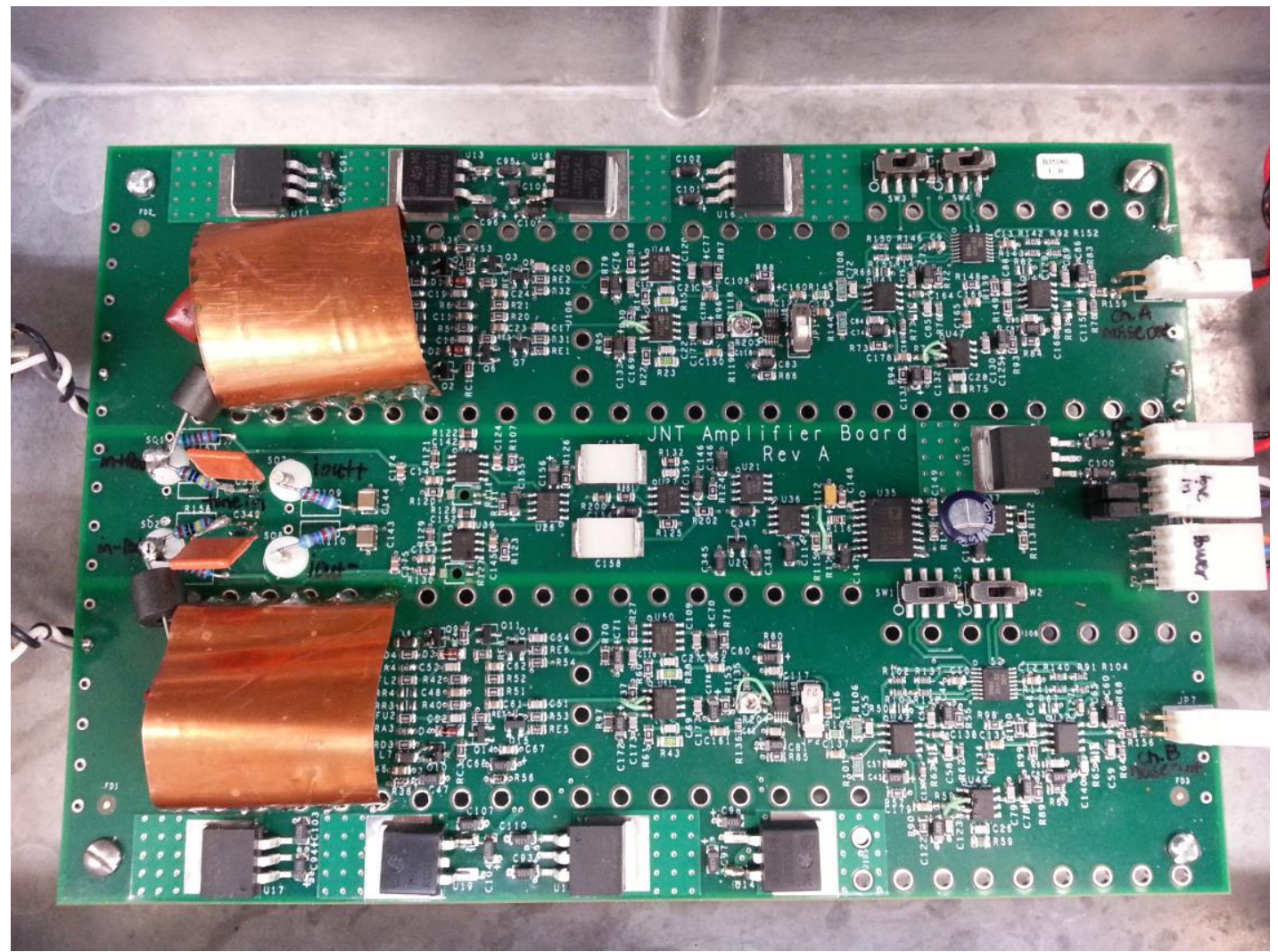

Fig. 9. JNT Amplifiers Module

operate asdescribed on the data sheet. There appeared to be a latch-up mode upon turn on of the module. This was remedied with a large capacitor across the device and can be seen in Fig. 9 on the middle-right side of the photo. If the board is refabricated in the future we would replace this part with another but presently have no plans to do this.

The next series of figures shows testing done with the module and current revision of software. The sensor is a 100-ohm platinum RTD on a 78-foot cable. A tube furnace was used to heat the RTD except at room temperature for which the RTD was simply left in the room. The system was calibrated at $291 \mathrm{C}$ and all screen shots are for the same calibration. The graphs on the lower right side of each screen shows the noise power spectral density for both pilot-tone (PTRPSD) and non-pilot-tone sweeps (NPTRPSD). They show the same shapes as each other with spikes showing some environmental noise. Details of the software will be presented in the next milestone report since the package is still in development. 


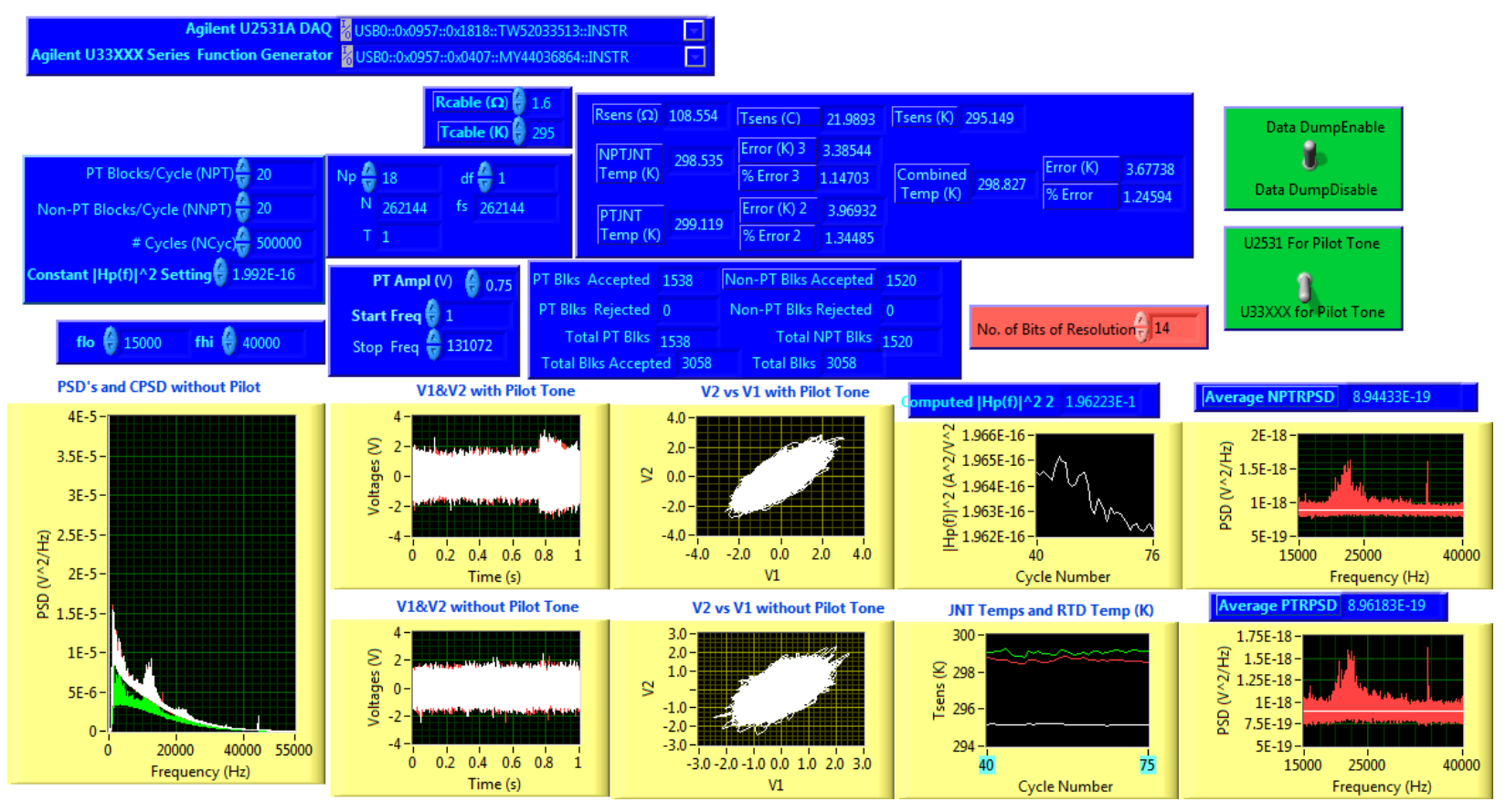

Fig. 10. Room temperature data (22C).

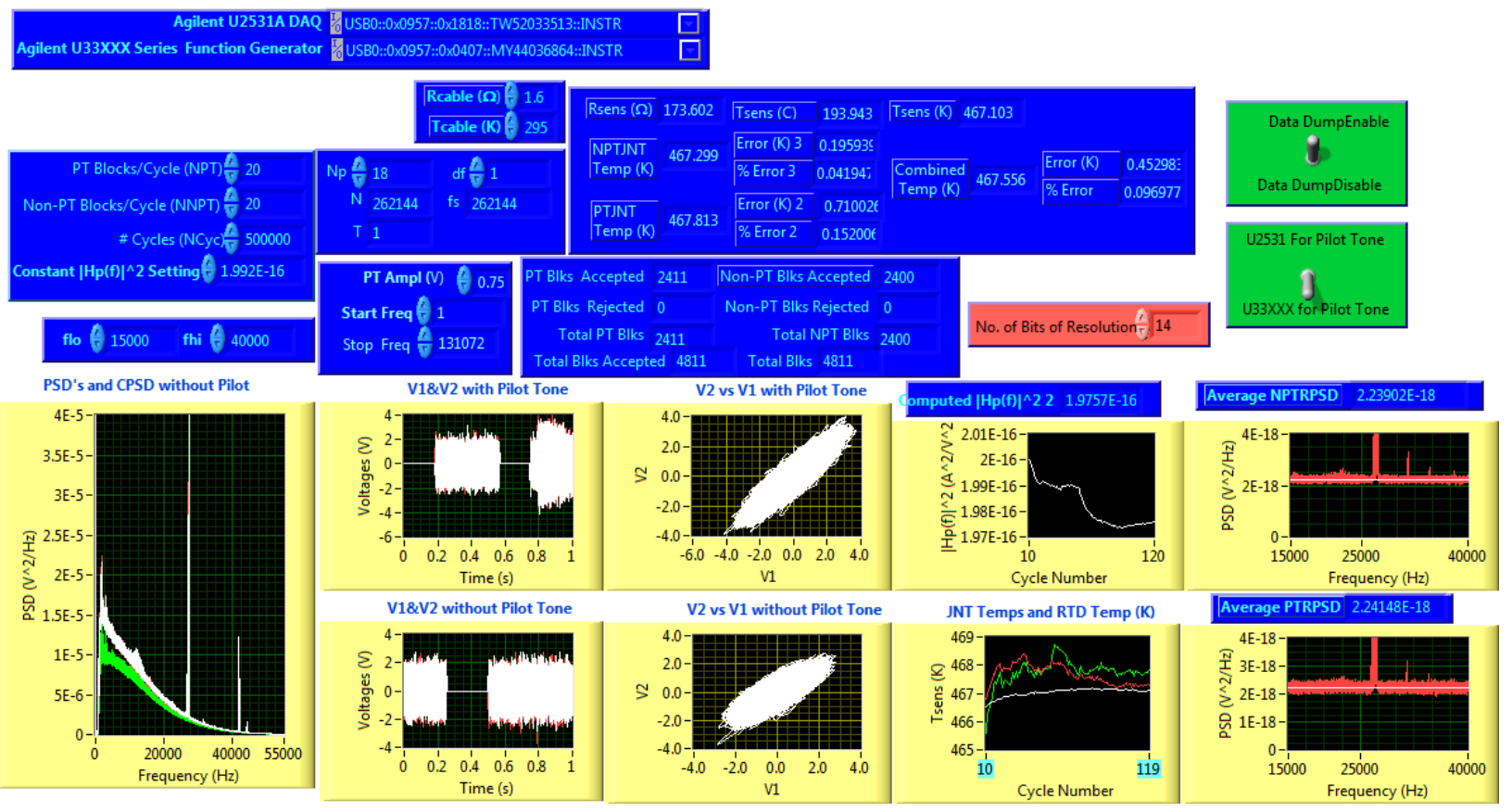

Fig. 11. 194C data. 


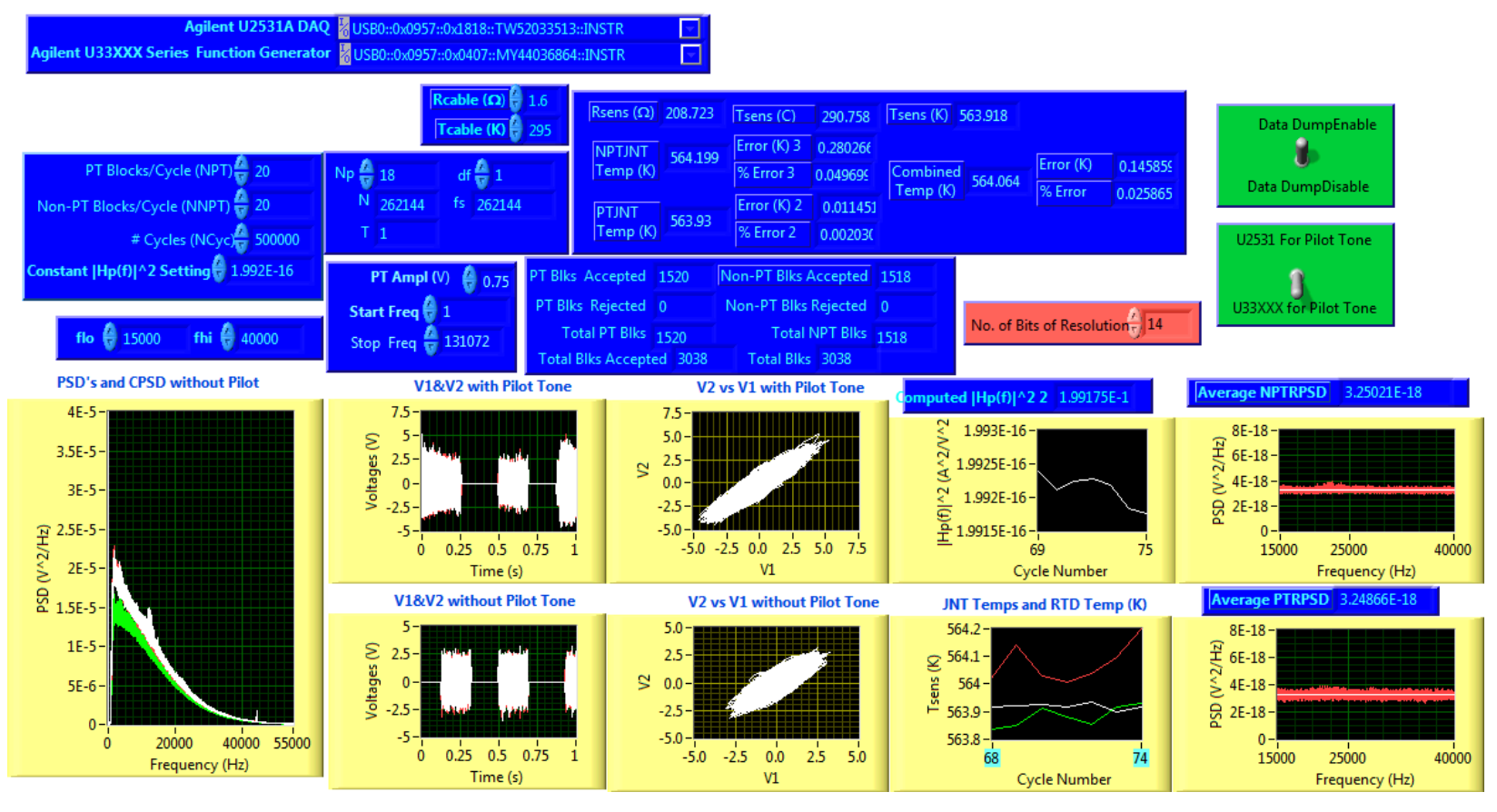

Fig. 12. $291 \mathrm{C}$ data.

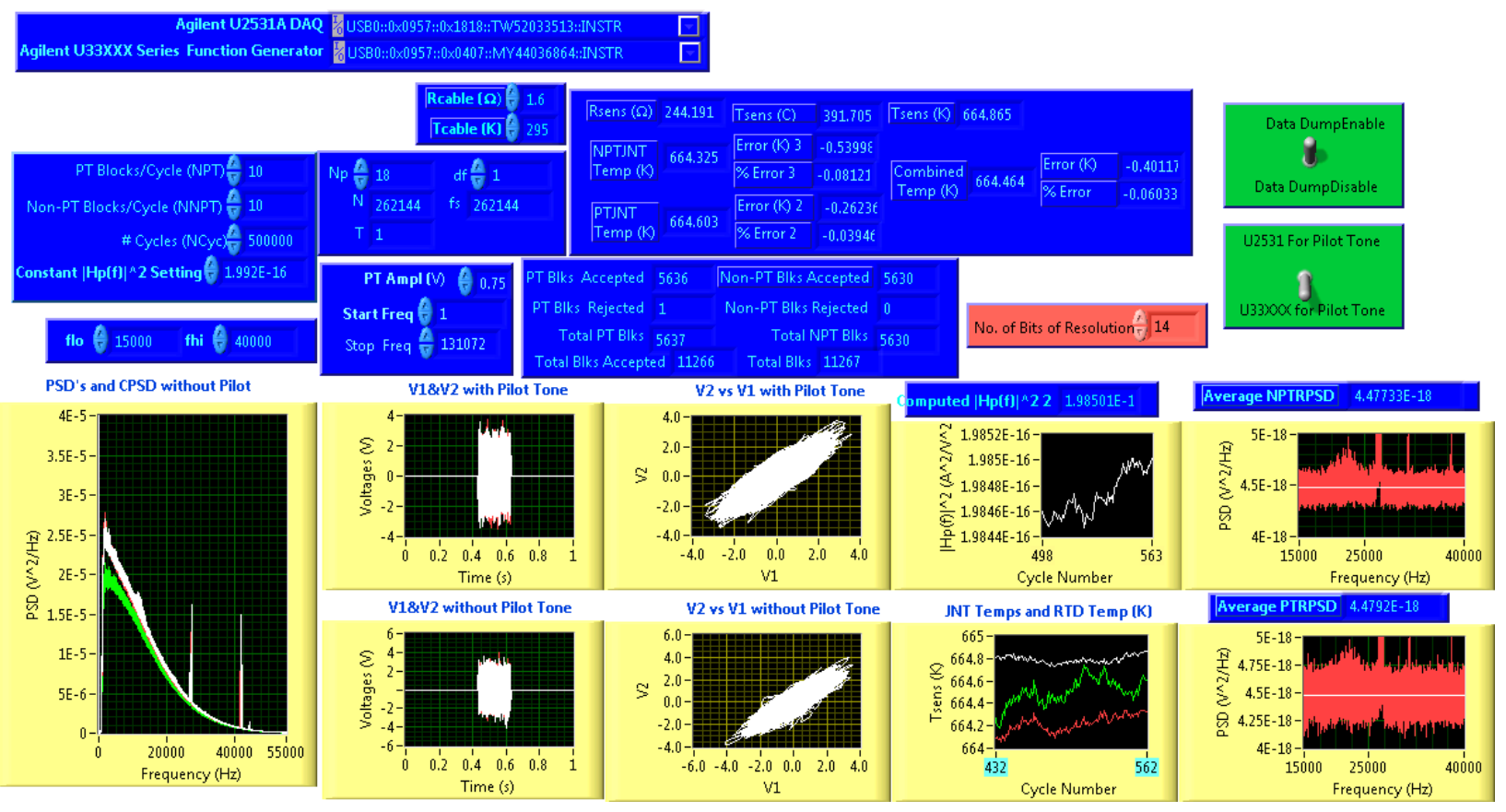

Fig. 13. 391C data. 


\section{CONCLUSION}

The front-end module was designed, constructed, and tested. The module contains the input amplifiers, gain, filtering, ohmmeter, and pilot-tone circuitry in a single box. Testing has shown that the device is working as designed and is presently being integrated into a chassis which will also contain the data-acquisition system.

\section{REFERENCES}

[1] Charles L. Britton, Jr., Michael Roberts, Nora D. Bull, Lou Qualls, and David E. Holcomb, "Johnson Noise Thermometry Requirements" ORNL/TM-2013/2, SMR/ICHMI/ORNL/TR-2013/01, January 2013

[2] Charles L. Britton, Jr., Michael Roberts, Nora D. Bull, , David E. Holcomb, and Richard T. Wood, "Johnson Noise Thermometry for Advanced Small Modular Reactors" ORNL/TM-2012/346, SMR/ICHMI/ORNL/TR-2012/01, September 2013 